Int. J. Electrochem. Sci., 14 (2019) 9755 - 9773

International Journal of

ELECTROCHEMICAL

SCIENCE

www.electrochemsci.org

\title{
Adiponitrile as a Novel Electrolyte Additive for High-Voltage Lithium-Ion Batteries
}

\author{
Liuyang Zhao ${ }^{1}$, Shilei Bian ${ }^{1}$, Zhicheng Ju ${ }^{1}$,Yongli Cui ${ }^{1}$, Yanhua Cui ${ }^{2}$,Yueli Shi ${ }^{1, *}$, Quanchao Zhuang ${ }^{1, *}$ \\ ${ }^{1}$ Li-ion Batteries Lab, School of Materials Science and Engineering, China University of \\ Mining \& Technology, Xuzhou 221116, China \\ 2 Institute of Electronic Engineering China Academy of Engineering Physics, \\ Mianyang, 621000, P. R. China \\ *E-mail: zwysyl@163.com
}

doi: $10.20964 / 2019.10 .27$

Received: 25 June 2019 / Accepted: 10 August 2019 / Published: 30 August 2019

In his study, we reported adiponitrile (ADN) as a novel electrolyte additive for the $\mathrm{LiNi}_{1 / 3} \mathrm{Co}_{1 / 3} \mathrm{Mn}_{1 / 3} \mathrm{O}_{2}$ cathode electrode in voltage ranges of 3.0-4.4 V, 3.0-4.6 $\mathrm{V}$ and 3.0-4.8 V. The electrochemical properties of the electrodes were investigated by linear sweep voltammetry (LSV), a charge/discharge test, electrochemical impedance spectroscopy (EIS) and X-ray photoelectron spectroscopy (XPS). The results of this study showed that adding ADN to the electrolyte could effectively enhance the reversible capacity and cycling performance of the cathode electrode. The initial discharge capacities were 167.8 $\mathrm{mAh} \mathrm{g}^{-1}$ and $214.8 \mathrm{mAh} \mathrm{g}^{-1}$ in electrolytes without and with $3 \% \mathrm{ADN}$, respectively. And the capacity retention rates were $68.4 \%$ and $70.4 \%$ at a voltage range of $3.0-4.6 \mathrm{~V}$ after 100 cycles in electrolytes without and with $3 \% \mathrm{ADN}$, respectively. The electrochemical performance was improved because of the compact and smooth solid electrolyte interface (SEI) film, which lowered the impedance between the cathode and the electrolyte by suppressing the decomposition of LiPF6 and improving the stability of EC. In addition, adding 3\%ADN to the electrolyte was favourable for obtaining a lower $R_{\mathrm{ct}}$, which could promote the charge-transfer process by suppressing the interfacial reaction between the electrode and electrolyte.

Keywords: ADN; Lithium-ion batteries; Electrochemical properties; Electrochemical impedance spectroscopy

\section{$\underline{\text { FULL TEXT }}$}

(C) 2019 The Authors. Published by ESG (www.electrochemsci.org). This article is an open access article distributed under the terms and conditions of the Creative Commons Attribution license (http://creativecommons.org/licenses/by/4.0/). 
